\title{
COMPORTAMIENTO DE PECES DULCEACUÍCOLAS EN CONTACTO CON Salmonella enteritidis var. danysz, LA HABANA, CUBA
}

\section{FRESHWATER FISHES BEHAVIOR IN CONTAC WITH Salmonella enteritidis var. danysz, La Habana.CUBA}

\author{
Natividad Hernández ', Aymara Torres ' , Margarita Ramírez 2, Israel García ', \\ Zulema Menéndez ${ }^{1}$ y Julia Castro $^{3}$
}

\section{RESUMEN}

Se evaluó durante 6 meses el comportamiento de 13 especies de peces de la fauna dulceacuícola cubana, que fueron puestas en contacto con Salmonella enteritidis var danyz en concentración de $10^{8}$ ufc/mL. En la evaluación se utilizaron los alevinos y juveniles procedentes de reservorios naturales, de la Estación de Guanímar y de Manpostón, ubicadas en Batabanó, Gaunímar, Guajaibón y La Lisa (Ciudad de la Habana). Antes de los ensayos, los peces fueron sometidos a 15 días de adaptación al cautiverio. Durante las evaluaciones, se registraron los parámetros fisicoquimicos del agua de los acuarios, detectándose incremento en los valores de nitritos y nitratos después de 48 horas de haberse colocado el inóculo. Se registraron los valores extremos de talla y peso de los peces, que comparados con el grupo control no evidenciaron diferencias significativas y al finalizar el ensayo todos los peces presentaron aspecto físico normal; por lo que se determinó que la dosis utilizada de Salmonella enteritidis var. danysz fue inocua para las diferentes especies de peces.

Palabras clave: Salmonella enteritidis, roedores, inocuidad, peces cautiverio.

\begin{abstract}
The behavior of 13 species of fresh water fish from Cuba in contact with Salmonella enteritidis var danysz in a concentration $10^{8} \mathrm{ufc} / \mathrm{ml}$ was evaluated for six months. In the evaluation use was made of alevines and juveniles from ponds in of the Guanimar and Manposton stations located in Batabanó, Guanimar, Guajaibon and La Lisa (Havanna city). Before the assay began, the fishes were put to a 15day period of adaptation to captivity. During the assays, physico-chemical parameters of the water from the ponds were recorded, and 48 hours after inoculation an increase in the amount of nitrites and nitrates was found. Extreme length and weight measurements of the fish were recorded, and no significant differences were found compared to the control group. At the end of the experiment all the fishes presented a normal aspect, which shows that the dose of Salmonella enteritidis var danysz made use of was harmless to the fishes.
\end{abstract}

Key words: Salmonella enteritidis, rodents, harmless, fishes, captivity.

\section{INTRODUCCIÓN}

Iil control de roedores sinantrópicos sobre la base de la patogenicidad selectiva de algunos microorganismos fue propuesto por primera vez a finales del siglo XLX por Pasteur,

Instituto de Medicina Tropical. Pedro Kouri. La Habana. Cuba. Laboratorio Control Biológico. E-mail: natividad@sld.cu.

2 Laboratorios Biológicos Farmacéuticos. La Habana. Cuba

3 Universidad Nac. Mayor de San Marcos. Lima-Perú. Fac. Ciencias Biológicas.
Mechnikov y Gamaleia. (Arzumanian et al., 1980).

Merezhkovski ( 1893) perfeccionó un medio de cultivo para conservar su virulencia. En 1897, Isachenko logró el aislamiento de bacterias enteropatógenas de ratas grises.

Danysz (1893) aisló durante una epizootia en roedores una bacteria que más tarde utilizaría en ratones de campo (LABIOFAM, 1995). El método bacteriológico de desratización ofrece mayores ventajas que los 
rodenticidas químicos porque requieren de una sola dosis, no crea rechazo en los roedoresplaga, es bíodegradable y es inocuo para los humanos y animales domésticos (Collazo y Castro, 1997). En Cuba, los estudios del control bacteriológico de los roedores se inició con Malushko, Espino y Acosta (1968), quienes realizaron diversas investigaciones, relacionadas con el control de roedores. Posteriormente se desarrolló la tecnología para la producción en condiciones tropicales del rodenticida biológico BIORAT (Espino et al., 1986). La enterobacteria Salmonella enteritidis var danysz (lisina negativa), utilizada como principio activo en el rodenticida posee características fisiológicas y moleculares que la diferencian de las formas patógenas del hombre. Actualmente el biopreparado ha sido aplicado en diversos objetivos con resultados satisfactorios (Villafaña et al.1995), y no se ha reportado ningún perjuicio para la salud del hombre, ni para los animales domésticos, como cerdos, aves, conejos y cuyes (Arzumanian et al.1969; Castro et al. 1996).

La lucha contra los roedores impone un desafío para todos los países. Se ha hallado una buena alternativa en el control biológico, a través del método microbiológico frente a los plaguicidas químicos, ya que provoca en ellos epizootias, que al parecer no perjudican a otras especies de animales (Espino, 1994). Debido al impacto del BIORAT en Cuba, América Latina y otras áreas geográficas donde se han patentado, resulta de gran interés observar el comportamiento de Salmonella enteritidis en organismos acuáticos como los peces, principales representantes de las especies dulceacuícolas, que constituyen fuente importante de proteínas para el hombre, además de ser esenciales componentes de la cadena alimentaria.

Por tal motivo, el objetivo principal de este trabajo fue valorar el comportamiento de diferentes especies de peces ante la presencia de Salmonella enteritidis var danysz (lisina negativa), componente básico del rodenticida biológico BIORAT.

\section{MATERIAL Y MÉTODOS}

\section{SELECCIÓN DE LAS ESPECIES DE PECES}

En el ensayo se utilizaron 13 especies de peces de la ictiofauna dulceacuícola cubana, de las cuales 6 son de consumo humano, 6 componentes de la cadena alimentaria y 2 peces ornamentales.

Las especies evaluadas fueron: Cubanichtys cubensis (Eigenman,1903); Gambusia punctata (Poey, 1854); Gambusia puncticulata (Poey, 1854); Girardinus metallicus (Poey, 1854), Girardinus falcatus (Eigenman, 1903); Rivulus cylindraceus (Poey, 1860); Poecilia reticulata (Peters, 1895); Cyprinus carpio comunis (Linnaeus, 1758); Cyprinus carpio especularis; Cichlasoma tetracanthus (Cuvier y Valenciennes, 1831); Dormitator maculatus (Bloch, 1790); Xiphophorus maculatus (Gunther, 1866) y Tilapia sp.

Para los bioensayos se consideraron los estadios más sensibles a cualquier producto tóxico, es decir, los alevinos y juveniles, así como las especies con una amplia área de dispersión geográfica, de diferentes grados de sensibilidad, determinados hábitos natatorios, etc.

\section{COLECTA Y TRASLADO DE LOS PECES}

Teniendo en cuenta las características de las especies se utilizaron dos tipos de colecta:

a) Los juveniles hembras y machos representantes de la ictiofauna dulceacuícola se encontraron habitando las orillas y reservorios naturales de poca profundidad. Se colectaron ejemplares de Poecilia reticulata y alevinos de algunas especies de agua abierta; la colecta se realizó con una red de $70 \mathrm{~cm}$ de largo y $50 \mathrm{~cm}$ de ancho, con una profundidad de $50 \mathrm{~cm}$ y un mango de 1,5 m de largo, hecho con malla plástica. La extracción se efectuó en espacios abiertos y en presencia de vegetación 
TABLA 1. Parámetros físico-químicos registrados durante los bioensayos.

\begin{tabular}{lcccc}
\hline ESPECIE & $\boldsymbol{p H}$ & $\boldsymbol{T}^{\circ}$ & $\mathrm{NO}_{2}$ & $\mathrm{NO}_{3}$ \\
\cline { 2 - 4 } & & $\left({ }^{\circ} \mathrm{C}\right)$ & $(\mathrm{mg} / \mathrm{L})$ & $(\mathrm{mg} / \mathrm{L})$ \\
Cubanichtys cubensis & 7,0 & 7,5 & 25 & 26 \\
Gambusia punctata & 7,0 & 7,5 & 25 & 26 \\
Gambusia puncticulata & 7,0 & 7,8 & 25 & 27 \\
Girardinus metallicus & 7,3 & 7,9 & 25 & 26 \\
Girardinus falcatus & 7,0 & 7,4 & 25 & 26 \\
Rivulus cylindraceus & 7,4 & 7,7 & 26 & 27 \\
Poecilia reticulata & 7,5 & 7,7 & 25 & 27 \\
Xiphophorus maculatus & 7,6 & 7,7 & 25 & 26 \\
Cyprinus carpio comunis & 7,6 & 7,8 & 25 & 26 \\
Cyprinus carpio especularis & 7,7 & 8,2 & 24 & 26 \\
Dormitator maculatus & 7,6 & 7,7 & 24 & 26 \\
Cichlasoma tetracantha & 7,6 & 7,7 & 21 & 23 \\
Tilapia sp. & 7,7 & 8,0 & 24 & 25 \\
\hline
\end{tabular}

emergente y flotante. Las localidades de colecta fueron Batabanó, Guanímar, Guajaibón y La Lisa (Provincia de La Habana). El traslado de los peces vivos hacia el laboratorio se realiz6 en recipientes de plástico de $15 \mathrm{~L}$ de capacidad con agua de los mismos lugares de colecta.

b) Los alevinos de peces comerciales de importancia en el consumo humano y de mayor talla que los del grupo anterior, cultivados en la estación de alevinaje de Guanimar y en la Empresa Acuícola, Mampostón (Provincia de La Habana), fueron capturados en cardúmenes, con redes de cerco; fueron pasados inmediatamente a un contenedor con agua de la presa, y se seleccionó los que se utilizarían para los bioensayos. Su traslado se realizó en bolsas de polietileno infladas con oxígeno.

Durante el traslado hubo mortandad, y se redujo el número de peces vivos. El resto fueron depositados durante 48 horas en acuarios que contenían agua declorada, para luego eliminar los muertos y los traumatizados (los cuales representaron el 4\% de Poecilia reticulata "guajacones" y el 10\% del resto). Fueron sometidos a observación periódica y se les aplicó tratamientos profilácticos, a base de cloruro de benzalconio durante 5 días alternos y se les administró una dieta alimentaria a base de pienso con alto contenido proteico. La alimentación fue suspendida 24 horas antes del bioensayo.

Se consideraron adaptados al cautiverio, aquellos peces capaces de tener un comportamiento con la etología de su especie; es decir, tener movimiento normal en el acuario, no experimentar saltos, y sobre todo que ingirieran alimento.

\section{ADAPTACIONES BIOECOLÓGICAS}

Los peces fueron observados, antes, durante y después del ensayo, con detenimiento para conocer sus reacciones, aspecto físico o cualquier otra anormalidad no acorde al comportamiento normal de la especie. Solamente en los peces comerciales se observaron síntomas de tensión, prolongados hasta 9 días después de su captura, siendo más evidente en Tilapia y Cichlasoma, mientras los alevinos de la presa Mampostón mostraron una gran agresividad, razón por la cual fue necesario situarlos en acuarios 
individuales; no sucedió así con Tilapia de Guanímar.

En general el período de adaptación fue de 15 días antes de comenzar el experimento.

\section{CONDICIONES PARA EL ENSAYO}

Conforme los peces se adaptaron a las condiciones de cautiverio, se ubicaron en acuarios de forma rectangular, de 3,15 y $25 \mathrm{~L}$, destinados a la evaluación. La masa de peces contenida en los acuarios fue de 0,5 - $1 \mathrm{~g} / \mathrm{L}$ de agua; según las normas OECD (5). Los "guajacones" se ubicaron por grupos, hembras y machos juntos, ocupando dos acuarios por especie, uno con los organismos que se iba a inocular y otro con los de control. En la Tabla 1 puede observarse la cantidad de individuos evaluados y los valores extremos de tallas y pesos de los peces. Las especies comestibles no agresivas (Cyprinidos, Dormitator y
Tilapia sp. de la Estación de Gaunímar) se situaron en dos o tres acuarios, según la disponibilidad de individuos, y uno de ellos se constituyó en el control (Tabla 2). Las agresivas (Cichlasoma y Tilapia sp. de la presa de Mampostón) se situaron en acuarios individuales. (Tabla 3).

Además de los grupos de ensayo (acuarios con peces), se utilizó un acuario control $\sin$ inoculo. Los acuarios se mantuvieron en el laboratorio, con temperaturas entre $22^{\circ} \mathrm{C}-26^{\circ} \mathrm{C}$, durante las 96 horas que duró el ensayo y con fotoperíodos de 12 horas de luz y 12 de oscuridad.

Considerando los requisitos establecidos para este tipo de experimento, antes, durante y 24 horas después del mismo, todos los días fueron registrados los parámetros físicoquímicos necesarios. La determinación del $\mathrm{O}_{2}$

TABLA 2. Longitud total y peso de la ictiofauna estudiada.

\begin{tabular}{lcccc}
\hline ESPECIE & INOCULADOS CONTROL & TALLA & PESO \\
C. cubensis & 7 & 7 & $\mathrm{~cm}$ & $\mathrm{~g}$ \\
G. punctata & 7 & 7 & $3,2-1,5$ & $0,2-0,15$ \\
G. punticulata & 10 & 10 & $3,0-4,8$ & $0,3-1,5$ \\
G. metallicus & 13 & 14 & $3,2-4,7$ & $0,2-1,1$ \\
G. falcatus & 7 & 7 & $3,0-3,2$ & $0,2-0,5$ \\
R. cylindraceus & 18 & 16 & $3,2-3,5$ & $0,5-0,6$ \\
P. reticulata & 15 & 16 & $1,7-3,5$ & $0,1-0,6$ \\
$X$. maculatus & 11 & 10 & $2,7-4,2$ & $0,4-1,3$ \\
\hline
\end{tabular}

TABLA 3. Longitud total y peso de las especies comestibles (no agresivas)

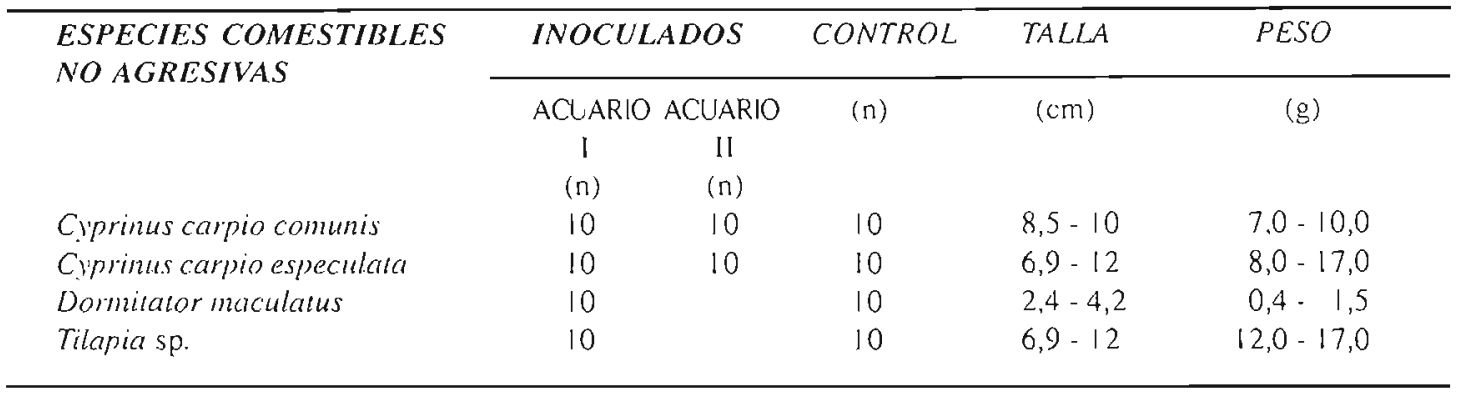


TABLA 4. Longitud total y peso de las especies comestibles (agresivas)

\begin{tabular}{|c|c|c|c|c|}
\hline \multirow{3}{*}{$\begin{array}{c}\text { ESPECIES COMESTIBLES } \\
\text { AGRESIVAS }\end{array}$} & \multicolumn{2}{|c|}{ INOCULADOS CONTROL } & TALLA & PESO \\
\hline & \multicolumn{2}{|c|}{ ACUARIOS INDIVIDUALES } & $(\mathrm{cm})$ & (g) \\
\hline & TOTAL (n) & $(\mathrm{n})$ & & \\
\hline Cichlasomateirachanlus & 9 & 9 & $9,5-10,5$ & $13,0-16,7$ \\
\hline Tilapia sp. & 10 & 10 & $6,0-10,0$ & $12,0-15,0$ \\
\hline
\end{tabular}

disuelto en el agua de los acuarios se realizó mediante un oxigenómetro Hanna. Los valores de amonio $\left(\mathrm{NH}_{4}+\right)$, nitritos $\left(\mathrm{NO}_{2}^{-}\right)$, y nitratos $\left(\mathrm{NO}_{3}^{-}\right)$fueron determinados con el Kit Aquamerck para determinaciones en agua. Para medir la temperatura ambiental, se utilizó un termómetro de máxima y mínima y en los acuarios fueron empleados termómetros de agua.

\section{PREPARACIÓN DEL INÓCULO}

Confirmada la pureza de la cepa de Salmonella mediante el estudio de sus características culturales, bioquímicas y serológicas, se inoculó en placas de Agar nutriente (BIOCEN), las cuales se incubaron a $35^{\circ} \mathrm{C}$ durante 24 horas. Transcurrido ese tiempo se realizó la suspensión con solución salina estéril 0,9\% y se comparó con la escala de Mac Farland (concentración 10* UFC de Salmonella enteritidis). Las muestras con la cantidad a inocular en cada acuario fueron depositadas en tubos estériles.

El ensayo se realizó utilizando el sistema estático directamente en el agua de los acuarios, aplicándose una dosis de $1 \mathrm{~mL}$ de inóculo por litro de agua, siendo $10^{\sharp} \mathrm{LFC} / \mathrm{mL}$ la concentración del inóculo. Se formaron dos grupos para los bioensayos y un acuario control.

1. Grupos tratados: Recibieron una dosis de 1 $\mathrm{mL}$ de inóculo $\left(10^{\mathrm{r}} \mathrm{ufc} / \mathrm{mL}\right)$ por litro de agua.

2. Grupos placebo: Recibieron $1 \mathrm{~mL}$ de solución salina estéril $0,9 \% / \mathrm{L}$ de agua.
3. Acuario control: Se utilizó un acuario control sin peces aplicándose $1 \mathrm{~mL}$ de inóculo por litro de agua, con el objetivo de validar el método utilizado en el aislamiento de la Salmonella del agua de los acuarios.

\section{RESULTADOS Y DISCUSIÓN}

El oxígeno en el agua se mantuvo por encima de $65 \%$ del valor de saturación del aire. Con relación al amonio no se detectó un incremento, pero sí con los nitritos $\left(\mathrm{NO}_{2}{ }^{-}\right)$, y nitratos $\left(\mathrm{NO}_{3}-\right)$ después de 48 horas de iniciado el ensayo. Esto ocurrió fundamentalmente en los acuarios donde se encontraban las "carpas" y "tilapias". Los valores $\mathrm{NO}_{2}$ y $\mathrm{NO}_{3}$ fueron 0,05-1 mg/L (ppm) y 50-100 mg/L (ppm) respectivamente. Los termómetros registraron una temperatura entre $23-25^{\circ} \mathrm{C}$ durante el ensayo, mientras que el $\mathrm{pH}$ se mantuvo entre 7,0-8,2.

Después de 78 horas de iniciada la evaluación de la toxicidad de la Salmonella enteritidis en peces, uno de los controles de Tilapia muri6, lo cual representa el 0,69\% de los animales no inoculados. A pesar de no haber recibido tratamiento, se realizó la siembra de sus órganos, y no se encontró ninguna evidencia clínica, a la cual pudiera atribuírsele su muerte. Es posible que, aunque su comportamiento fue normal después de la aclimatación incluyendo la ingestión de alimento, parece que solo fue aparente la adaptación, ya que se trataba de uno de los alevinos de Tilapia considerados agresivos, y -como se señaló anteriormente- estos peces 
tuvieron un período de adaptación más dificultoso.

Seis meses después de los ensayos, los peces restantes se compararon con los controles, y se comprobó que se encontraban en perfectas condiciones, mostrando aspecto físico normal; en ningún pez se observó falta de reacción, pérdida del equilibrio, ni ningún otro rasgo visual que no fuese acorde con el comportamiento normal de la especie.

\section{LITERATURA CITADA}

Arzumanian G., Espino R. 1980 Mélodos bacteriológicos de lucha conera roedores dañinos. ACC; $28: 1$ 37 (Serie Biológica).

LABIOFAM. 1995. Importancia socioeconómica del rodenticida biológico BIORAT para el control de roedores dañinos. Folleto de divulgación

Espino R, Montero G, Villafaña V y Bornote J. 1986. Normas técnicas para la producción de Salmocumárín en Cuba. Bol. Hig. Epidemiol. 4 $1-25$.
Villafaña F, Montero G, Díaz M y Bornote J. 1995. Eleclividad del rodenticida Salmocumarín en objetivos pecuarios y urbanos. Rev. Cubana Med. Trop.47(2):83-88.

OECD. 1992. Guidelines for testing chemicals. Fish Acute toxicity lest ; 203: 1-9.

Camacho, C. 1993. The fresh water fishes of Western Cuba. US. Comn. Of ISO 6579 Microbiology. General guidance on methods tor the detection of Salmonella.

Garcia, I.; Novikov, J y Finalé, M. 1984. Algunos aspectos biológicos pesqueros de la Tilapia (Oreochremis aureus) en las lagunas costeras de Tunas de Zaza. Cuba. Rev. In. Mar. 5: 65-76.

Collazo, R y Casiro J. 1997. Los roedores dañinos: algunos aspectos del control químico y bacteriológico. Rev. Inv. Pec. IVITA (Perú) 8(1): $1-9$.

Castro, J.; Melo, D.; Diestro A: Alzamora, L. y Medina, R. 1997. Determinación cle inocuidad de la Salmonella enteritidis biovar $1-7 F 4$ en animales domésticos. Rev. SCIENTA OMNI (UNMSM) I(3): 217-235. 